\title{
Nomenclátor Geográfico de Andalucía
}

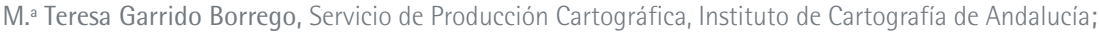

Cristina Torrecillas Lozano, Dpto. de Ingeniería Gráfica, Escuela Técnica Superior de Ingenieros, Universidad de Sevilla

El Decreto 141/2006, por el que se ordena la actividad cartográfica en la Comunidad Autónoma, y el Plan Cartográfico de Andalucía 2009-2012 han impulsado en el Instituto de Cartografía de Andalucia (ICA) el desarrollo, implantación y mantenimiento del Nomenclátor Geográfico de Andalucia (NGA), considerado como una infraestructura y un equipamiento geográfico de referencia del Sistema Cartográfico de Andalucía.

El proyecto NGA se ha concebido como un conjunto de bases de datos de nombres geográficos normalizados relativos al territorio andaluz, considerando como fuente inicial la toponimia incluida en el Mapa Topográfico de Andalucía 1:10.000 (MTA10), a la que se va incorporando la toponimia de otras fuentes documentales y orales que proporcionan nuevos nombres o contribuyen a su normalización. Su estructura sigue el Modelo de Nomenclátor de España (MNE) para facilitar su armonización con el Nomenclátor Geográfico Básico de España e integración con el futuro Nomenclátor Geográfico Nacional, en los términos definidos en el RD 1545/2007, referido al Sistema Cartográfico Nacional. Su finalidad es almacenar y gestionar los nombres geográficos andaluces siguiendo los estándares, las recomendaciones y la normativa nacional o europea al respecto, en especial la relacionada con INSPIRE.

Se inicia en 2004 con la realización de la Base de Datos de Topónimos de Andalucia 1:10.000 (BTA10), procedente de la toponimia del MTA10 (Digital Vectorial v1:1998-2003). Una vez finalizada esta base de datos en 2007, se procede a su adaptación al Modelo de Nomenclátor de España con objeto de servir como primera fuente a integrar en el Nomenclátor Geográfico de Andalucia. Actualmente contiene unos 150.000 topónimos e identificadores geográficos clasificados temáticamente en áreas administrativas, entidades de población, hidrografía, orografia, patrimonio, infraestructuras, actividades industriales o extractivas, servicios y equipamientos.

Dichos topónimos han sido georreferenciados con una geometria puntual, conteniendo unas 205.000 localizaciones puntuales resultado de ofrecer un punto por cada municipio y hoja a escala 1:10.000 en los que se encuentra la entidad geográfica, mediante coordenadas $X$ e $Y$, huso 30 en el Sistema de Referencia Europeam Datum 1950 (EPSG: 23030).

El modelo de datos del NGA consta de las tablas y listas controladas obligatorias del MNE, más una serie de tablas específicas y necesarias para la gestión interna en el ICA: control interno de incidencias en el topónimo según la fuente de captura de datos utilizada, clasificación de los nombres según la escala o resolución en las salidas gráficas y codificación geográfica más detallada del tipo de entidad o elemento geográfico.

Tras una primera fase de carga de la BTA10 se ha continuado con la captura de toponimia de otras fuentes documentales y orales, como la toponimia catastral o información proporcionada por técnicos y vecinos municipales, trabajos que culminarán con la progresiva recogida y comprobación en campo.

En paralelo y en coordinación con la Comisión Especializada de Nombres Geográficos del Consejo Superior Geográfico, se realizan tareas de normalización. Esta labor es absolutamente necesaria para resolver los problemas de la diversidad o confusión en la denominación de muchos microtopónimos. La disponibilidad de nombres geográficos normalizados que permitan identificar univocamente los diferentes elementos geográficos, sin perjuicio de la recogida de la riqueza de las variantes existentes, es imprescindible para el buen uso de los nomenclátores en los sistemas de información geográfica y en las Infraestructuras de Datos Espaciales.

En 2008, con objeto de lograr una gestión integral, ágil, eficiente y segura, se inicia el diseño de una base de datos en Oracle y una aplicación en un entorno web. Esta aplicación permite la introducción y consulta de datos, la elaboración de informes estadísticos, la importación o exportación de registros para grandes peticiones, la gestión de usuarios y la publicación de los topónimos a través de dos servicios web sincronizados que siguen las especificaciones del Open Geospatial Consortium (OGC) Web Feature Service - Gazetteer (WFS-G) y Web Feature Service (WFS): el Buscador de nombres geográficos, y el Servicio interoperable de nomenclátor WFS. El primero, implantado en abril de 2008 con un uso más divulgativo, permite consultar por nombre, tipo de entidad o zona geográfica asi como descargar los topónimos consultados y hacer propuestas de rectificación toponímica de manera que se hace copartícipe a la ciudadanía en la mejora de la calidad de los datos. El segundo, implantado en diciembre de 2009 y desarrollado en el software libre Deegree 2.2, ofrece una vista mínima de campos obligatorios (identificador, nombre, tipo de entidad y localización expresada en coordenadas, provincia y municipio), siendo utilizado a un nivel más técnico con distintos clientes ligeros y pesados 

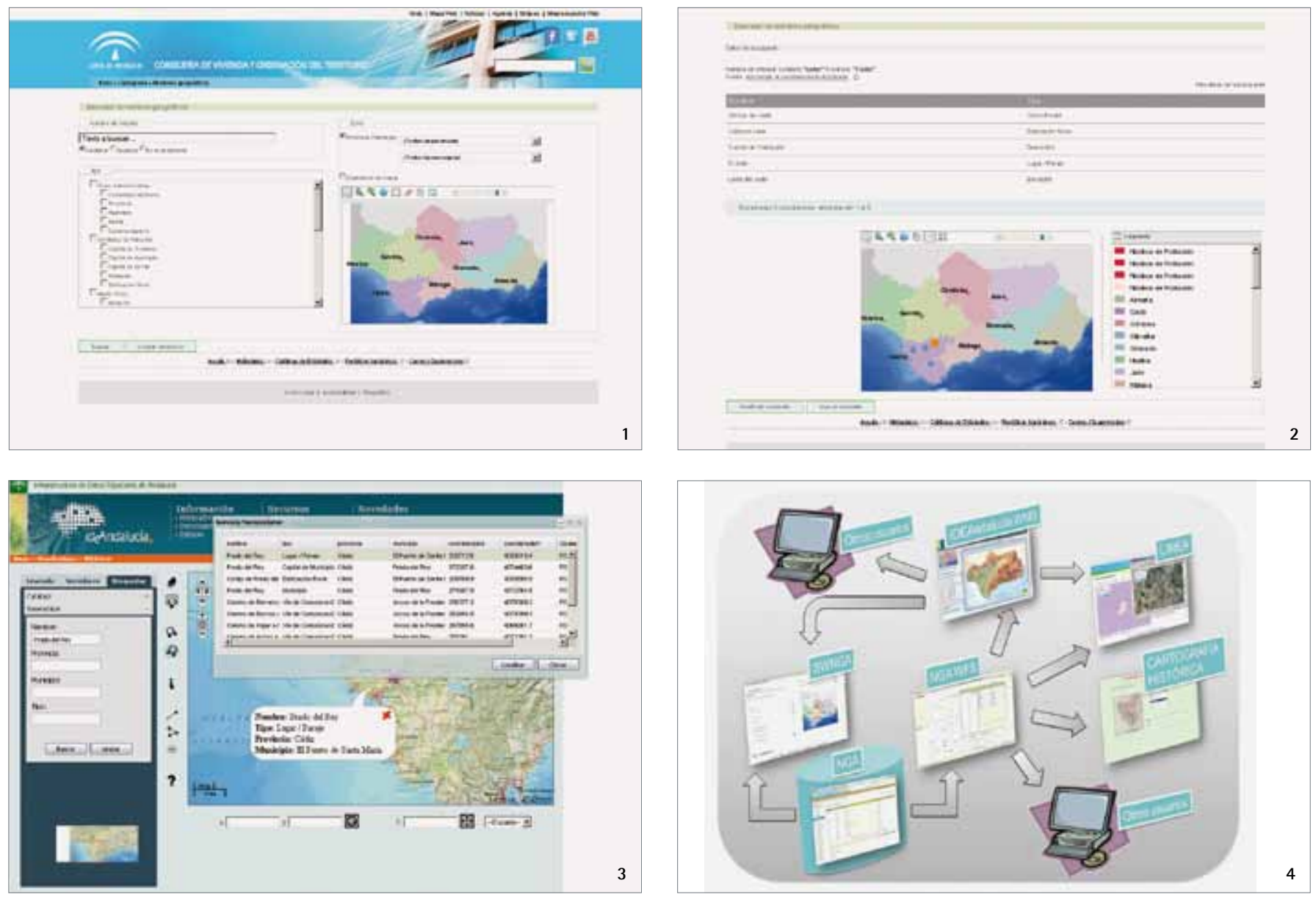

1. Página principal del Buscador de nombres geográficos. Fuente: www.juntadeandalucia.es/viviendayordenaciondelterritorio/nomenclator/buscador.jsp?lang=esp 2. Resultados de una consulta en el Buscador de nombres geográficos. Fuente: www.juntadeandalucia.es/viviendayordenaciondelterritorio/nomenclator/buscador.jsp? lang=esp 3. Uso del Servicio de nomenclátor WFS en la Búsqueda por nomenclátor de la IDEAndalucia. Fuente: www.ideandalucia.es

4. Esquema de interoperabilidad del servicio de nomenclátor del ICA.

como OpenJUMP, GvSIG o ArcGIS. En la página web de la IDEAndalucia se puede descargar un documento que orienta sobre el uso del servicio de nomenclátor WFS.

El proyecto NGA pretende normalizar y simplificar los procesos de inventario, normalización y difusión de la toponimia andaluza, competencias del ICA, al utilizar y compartir una única base de datos, gestionada por un único responsable y disponible o compartida por distintas aplicaciones del Sistema Cartográfico de Andalucia, entre ellas IDEAndalucia o el catálogo on-line para localizar información espacial de Andalucia (LINE@), en aras de un mejor y más eficiente servicio público, ya que la finalidad última del NGA es la de servir de referencia normalizada de la toponimia de Andalucia.

\section{Documentos y webs de referencia}

DECRETO 141/2006, de 9 de agosto, por el que se ordena la actividad cartográfica en la Comunidad Autónoma de Andalucía. Boletín Oficial de la Junta de Andalucía, n. ${ }^{\circ} 154$, de 9 de agosto de 2006

DIRECTIVA 2007/2/CE del Parlamento Europeo y del Consejo por la que se establece una infraestructura de información espacial en la Comunidad Europea (Inspire). Diario Oficial de la Unión Europea, n. ${ }^{\circ}$ 108, de 25 de abril de 2007 D2.8.I.3 INSPIRE Data Specification on Geographical names - Guidelines [en linea], v 3.0.1 03.05.2010 < http://inspire.jrc.ec.europa.eu/documents/
Data_Specifications/INSPIRE_DataSpecification_GN_v3.0.1.pdf> [consulta: 24/09/2010]

MODELO de Nomenclátor de España (MNE) v 1.2 [en linea] < http://www.idee.es/ resources/recomendacionesCSG/MNEv1_2.pdf > [24/09/2010]

PLAN Cartográfico de Andalucía 2009-2012 aprobado por Consejo de Gobierno de 16 de septiembre de 2008. Boletín Oficial de la Junta de Andalucía, n. 215 , de 29 de octubre de 2008

REAL DECRETO 1545/2007, de 23 de noviembre, por el que se regula el Sistema Cartográfico Nacional. Boletín Oficial de la Junta de Andalucia, n. ${ }^{\circ} 287$, de 30 de noviembre de 2007

\section{Buscador de nombres geográficos}

$<$ http://www.juntadeandalucia.es/viviendayordenaciondelterritorio/nomenclator/> Infraestructura de Datos Espaciales de Andalucía. Búsqueda por Nomenclátor <http://www.ideandalucia.es/index.php/es/servicios/descargawfs/49-servicios-de-busqueda-de-nombres-geograficos/168-nomenclatorgeografico-de-andalucia>

Gazetteer Service - Application Profile of the Web Feature Service Implementation Specification <http://portal.opengeospatial.org/files/?artifact_id=15529>

Instituto de Cartografía de Andalucía

<http://www.juntadeandalucia.es/vivienda yordenaciondelterritorio/cartografia> OpenGIS Web Feature Service (WFS) Implementation Specification

$<$ http://portal.opengeospatial.org/files/?artifact_id=8339>

Servicio de nomenclátor WFS

$<$ http://www.juntadeandalucia.es/viviendayordenacion delterritorio /WFS/ Nomenclator/services?> 